\title{
Escritas e escribas: o cuneiforme no antigo Oriente Próximo
}

\author{
KATIA MARIA PAIM POZZER \\ Universidade Luterana do Brasil - ULBRA/RS
}

\begin{abstract}
RESUMO: A idéia da escrita surgiu ainda na pré-história, mas os documentos mais antigos conhecidos datam de 3.200 a.C. São tabletes de argila com escrita cuneiforme e foram encontrados na cidade de Uruk, no sul da Mesopotâmia. A escrita cuneiforme teve uma grande difusão no mundo antigo oriental, tendo sido utilizada na Baixa Mesopotâmia, correspondendo ao atual Iraque, à região da Assíria e da Babilônia e às regiões periféricas, localizadas, atualmente, na Síria, Planalto Anatólico, Armênia, Irã, Chipre, Palestina e mesmo no Egito. Porém, essa escrita, provavelmente, nunca foi "popular", no sentido etimológico do termo: ela sempre permaneceu no domínio de um grupo restrito de especialistas - os escribas - devido às suas dificuldades intrínsecas, que exigiam dedicação e muito tempo para sua aprendizagem. A escola era chamada de é.dub.ba., em sumério e bît ÿuppi, em acádico, literalmente traduzido por "casa dos tabletes". Foi criada com a finalidade de formar os escribas para trabalharem nas tarefas econômicas e administrativas do país, sobretudo do templo e do palácio. Porém, com o tempo, ela se tornou um centro de difusão da cultura e do saber.
\end{abstract}

PALAVRAS-CHAVE: Escrita cuneiforme; Mesopotâmia; escriba; acádico; sumério; antigo Oriente Próximo.

\section{Introdução}

A idéia da escrita' surgiu ainda na pré-história, pois, desde o período neolítico e durante milênios, o homem praticou sistemas de contabilidade utilizando símbolos numéricos que serviam de auxílio na administração dos bens produzidos.

A descoberta e a difusão da agricultura e da criação de gado durante o período neolítico (7.000-4.000 a.C. aproximadamente) favoreceram o processo de sedentarização das comunidades nômades e de formação de novas organizações da sociedade. No final dessa fase, conhecida como Revolução Urbana, ocorreu um importante salto no que se refere à organização, havendo separação entre a produção agrícola primária e a produção artesanal especializada.

O desenvolvimento da agricultura gerou um aumento das reservas alimentares, possibilitando uma maior especialização das atividades artesanais e técnicas, acentuando a divisão social do trabalho. A humanidade passou a ter uma maior garantia da sua sobrevivência material e pôde consagrar-se a outras tarefas: o tempo tornou-se, então, uma nova 
riqueza, da qual tirou proveito para refletir e, assim, acelerar a marcha das descobertas e invenções decisivas que marcaram essa época (Margueron, 1991, p. 155).

O nascimento da escrita inscreve-se nesse contexto histórico, com essa nova percepção de tempo e de espaço por parte das populações que ocupavam as planícies aluviais da Baixa Mesopotâmia (fig. 1).

O estudo da escrita cuneiforme conheceu um importante impulso com as descobertas arqueológicas realizadas, sobretudo, nos últimos cinqüenta anos, que trouxeram à luz uma enorme quantidade de documentos, levando a um conhecimento mais preciso desta escrita e das diversas línguas antigas que dela se utilizaram. Atualmente, o domínio desta escrita é considerado uma condição indispensável para a qualificação do trabalho do historiador nessa área.

\section{Origens da escrita cuneiforme}

Os documentos mais antigos conhecidos até hoje foram encontrados em um templo na cidade de Uruk, com data aproximada de 3.200 a.C. São tabletes de argila com escrita cuneiforme, apresentando sinais pictográficos.

O nome da escrita cuneiforme vem do latim cuneus (canto), pois ela é o resultado da incisão de um estilete, impressa na argila mole, com três dimensões (altura, largura e profundidade). A escrita cuneiforme foi utilizada para se gravar em paredes de rochedos, corpos de estátuas e grandes monumentos, sendo sempre as inscrições um decalque do texto escrito no tablete de argila ${ }^{2}$. Lê-se um texto em escrita cuneiforme da esquerda para a direita e de cima para baixo, como em português.

Através de evidências materiais, foi possível elaborar-se uma seqüência cronológica do desenvolvimento do sistema de representação mesopotâmico. Para fins didáticos, será utilizada uma divisão em três estágios diferentes.

\subsection{Estágio I}

Este estágio é, também, chamado de estágio das fichas ou calculi, que eram símbolos numéricos cuja forma variava segundo o objeto a que correspondiam (fig. 2). Fabricados em argila, podiam reproduzir objetos concretos ou ter representação convencional; os documentos mais antigos deste estágio datam do sétimo milênio a.C.

\subsection{Estágio II}

Este estágio é caracterizado pela utilização de esferas, confeccionadas em argila mole, apresentando impressões de fichas, marcas de numerais e a aposição do selo de quem as teria emitido (fig. 3). Em geral, essas esferas tinham o tamanho aproximado de uma bola de tênis, sendo que as mais antigas datam do quarto milênio a.C.

\subsection{Estágio III}

Neste estágio, surgiram os primeiros tabletes de argila, como se a esfera de argila tivesse sido aplainada (fig. 4). Os tabletes mais antigos datam do quarto milênio a.C. Passaram-se a imprimir selos-cilindros ${ }^{3}$ nesses tabletes como garantia de sua autenticidade a partir da segunda metade do quarto milênio a.C. Esses selos, como o seu nome indica, possuí- 
am forma cilíndrica e eram confeccionados em pedra, cerâmica, vidro, argila cozida, madeira, marfim ou metal. Eram esculpidos com motivos que representam uma importante fonte de informação sobre a iconografia da mitologia e da vida cotidiana dos mesopotâmicos.

\section{Desenvolvimento do sistema cuneiforme}

O sistema gráfico cuneiforme nasceu de um longo processo de criação e conheceu uma evolução que se fez sentir não somente na paleografia, como também na utilização dos sinais. Pode-se, então, dividir esse processo em duas grandes etapas: a pictográfica e a silábica (Durand, 1977, p. 20).

\subsection{Etapa pictográfica}

$\mathrm{Na}$ etapa pictográfica, realizavam-se representações picturais dos objetos. $\mathrm{O}$ pictograma (desenho) ainda não era uma escrita, porque ele simbolizava uma coisa e não uma palavra. Podia-se compreender a mensagem, mas não lê-la. É o que Bottéro (1987, p. 89) chamou de aide-mémoire (ajuda à memória). Estima-se que havia, aproximadamente, 1.500 pictogramas repertoriados, dos quais mais de 300 eram próximos dos sinais cuneiformes que lhes sucederam, indicando que houve uma certa continuidade entre essas experiências.

Imaginem-se esses primeiros textos. Por exemplo, a seguinte frase: $O$ rei está morto. Para realizar-se este tablete pictográfico, pode-se desenhar um homem maior que os outros olhando para o oeste. Porém, para decodificar-se a mensagem, precisa-se conhecer:

a) o simbolismo da época: o homem maior representa o rei; oeste representa a morte ou a região dos mortos;

b) a ordem dessa simbologia: rei morto (e não rei dos mortos);

c) a realização fonética: pronunciar a frase.

Está-se diante de um quadro de conteúdo simbólico, que possui o sentido procurado enquanto globalidade. Pode-se considerá-lo uma frase-ideograma, assim como muitas das representações da época pré-histórica.

Neste estágio pictográfico, há tantos quadros quantas frases. Em vista dos problemas de realização material e da restrição dos elementos combinatórios (orientações, dimensões, cores, etc.), bem como de suas imprecisões, o corpus ideográfico é, certamente, bastante limitado.

\subsection{Etapa silábica}

Na etapa silábica, tem-se a representação estilizada dos objetos. O sistema gráfico é não mais uma escrita de coisas, mas uma escrita fonética da palavra. Ele não se limita a relembrar ou a comemorar o conhecido; agora, é, também, capaz de transmitir novos conhecimentos e de instruir o homem. Para isso, foi preciso incorporar o instrumento mais perfeito da análise e da comunicação do real pelo homem: a língua falada.

Tome-se, como exemplo, o pictograma da idéia de pé, que se dizia $d u$, em sumério, palavra que também designava outra coisa: verdadeiro, correto. Constata-se o rompimento da relação primeira desse sinal com um objeto (o pé), para guardar o fonema (du), que fazia parte unicamente da língua falada. Enquanto pictograma, o sinal do pé refere-se à coisa pé, ou, na qualidade de ideograma, a várias coisas evocadas por ele, como ir, manter-se de pé, 
caminho, etc. Mas o som $d u$ designa, com precisão, esse fonema, onde quer que ele se encontre na fala, como, por exemplo, para escrever-se Igi.du, o deus Palil. O sinal deixa de ser pictograma ou ideograma para tornar-se um fonema.

Essa etapa fonética viu surgirem duas línguas completamente diferentes: o sumério e o acádico. Os tabletes encontrados na cidade de Ur e datados de 2.800 a.C. foram os primeiros documentos em sumério escavados.

O sumério é uma língua aglutinante, monossilábica, composta de palavras que não se modificam. O acádico, que surgiu na metade do terceiro milênio a.C., no sul da Mesopotâmia, é uma língua semítica, flexionada, cujas palavras se modificam.

A fig. 5 mostra a evolução dos sinais cuneiformes: na primeira linha, a forma pictográfica (3.000 a.C.); na segunda linha, o sumério clássico (2.400 a.C.) e, na última linha, o neoassírio (650 a.C.).

Pode-se concluir que a partir do momento em que a representação gráfica impede o desenho de ser espontaneamente evocador e o estiliza, transformando-o em convenção e não mais exigindo o seu reconhecimento, mas sua memorização, a ruptura com a arte é consumada e nasce a escrita.

\section{As línguas mesopotâmicas}

\subsection{Sumério}

O sumério tem, originalmente, uma base ideogramática. Podemos definir o ideograma como um sinal contendo, ao mesmo tempo, um sentido e um som.

Na língua suméria cada idéia básica - nominal ou verbal - é expressa por uma sílaba estável ou várias sílabas. O verbo caracteriza-se por ter uma raiz fixa, que não é suscetível de alterações vocálicas ou de infixidez consonântica, e esta é uma diferença essencial com relação ao acádico. Para obterem-se formas conjugadas, é preciso prefixar-se o verbo (a raiz) com diversas bases e incluírem-se infixos entre a base e a raiz. Por exemplo: a raiz $z u$ significa saber; para conjugar-se o verbo, adiciona-se a base $m u$, dando $m u . z u$ (ele soube); com nu.mu.zu, tem-se a frase negativa (ele não soube).

A língua suméria utiliza apenas quatro vogais, $a, e, i, u$, duas semivogais, $w, y$, e diversas consoantes: $b, d, g, k, l, m, n, p, r, s, t, z, h, \breve{s}$.

A estrutura básica da frase é: sujeito/ complemento/ verbo. Nesta etapa, o símbolo global do estágio pictográfico vai dar lugar a uma justaposição de símbolos unívocos: o ideograma está, então, ao nível da palavra. Os elementos combinatórios vão crescer indefinidamente, tornando-o um sistema muito pesado, pois há tantos sinais quantas palavras a serem escritas na língua (Thomsen, 1984).

A maior parte dos ideogramas foi criada de maneira simples, desenhando-se o objeto a ser evocado. Em um primeiro momento, a grafia do sinal está de acordo com as convenções do desenho na arte suméria de então, como, por exemplo, a palavra jardim, que guarda o princípio da "não-perspectiva" para representar as árvores (fig. 6).

Um nível mais elaborado é alcançado quando se faz necessária a notação de realidades não-figurativas, como, por exemplo, as palavras amigo e inimigo (fig. 7). Vê-se, então, o papel da simbolização extraída das convenções sociais. Amigo é representado por duas linhas paralelas, o que transmite uma idéia de "companheirismo, estar junto"; já inimigo é representado por duas linhas que se cruzam, denotando "rivalidade, conflito". 
No período sumério arcaico, o sistema global é substituído pela justaposição de sinais. Se a arte suméria continua a representar o rei como um ser maior, a escrita exprimeo pela justaposição dos sinais $l u$ (homem) e gal (grande), lendo-se o conjunto como lugal (rei). Podem-se ver outros exemplos do sistema de justaposição de dois ou mais sinais, como mostra a fig. 8: boca + mão = rezar (šud); boca + água = beber (nag).

Os sumérios criaram, ainda, os chamados "sinais complexos" a fim de limitarem o seu inventário, o que pode ser exemplificado com a representação da fig. 9.

Para este mesmo ideograma que, graficamente, é uma cabeça com uma marca na região inferior do rosto, obtêm-se as seguintes pronúncias e sentidos: $\mathrm{KA}=$ boca; $\mathrm{KIR}=$ nariz; $\mathrm{ZU}=$ dente; INIM = palavra; $\mathrm{GU}=$ grito; $\mathrm{DU}=$ falar.

Este fenômeno é chamado de polifonia e caracteriza-se pela existência de vários sons para um mesmo sinal. A polifonia dos sinais sumérios representa uma das maiores dificuldades para sua compreensão. Contudo, ao mesmo tempo, o sumério é uma língua largamente monossilábica e possui um grande número de homófonos, sinais cuneiformes diferentes que representam o mesmo som (fig. 10). Assim, por exemplo, há 11 maneiras diferentes de se escrever o som $d u$.

Cada grafia diferente indica um sentido geral. Para tornar possível a edição por transliteração, que é a passagem do sinal cuneiforme para os caracteres latinos silábicos, foi criado um sistema, pelo filólogo francês François Thureau-Dangin, que consiste em se numerar os homófonos de 1 ao infinito. Como no exemplo acima, o "1" não tem nenhuma marca $(d u)$, o "2" tem acento agudo $(d u ́)$, o "3" tem acento grave (dù) e os outros têm índices numéricos começando a partir do $4\left(\mathrm{du}_{4}, \mathrm{du}_{5}\right.$, etc.).

Essas informações estão contidas nos dois silabários existentes - um em língua francesa, outro em língua alemã - que são uma ferramenta de trabalho indispensável para o especialista (Labat, 1988 e Borger, 1971, 1978 e 1981).

\subsection{Acádico}

O acádico é uma língua semita, juntamente com o árabe, o hebreu, o aramaico, etc. É uma língua flexionada, ou seja, as palavras modificam-se com a adição de prefixos, sufixos, infixos e desinências diversas e seu sentido varia. $\mathrm{O}$ acádico teve três grandes dialetos: acádico antigo, babilônico e assírio (Hallo, 1996, p. 38).

Em acádico, o sentido geral de uma palavra é definido pela raiz composta de três consoantes em ordem fixa. A estrutura básica da frase foi herdada do sumério: sujeito/ complemento/ verbo. A língua acádica usa as mesmas vogais do sumério: $a, e, i, u$; as semivogais são $w, y$; e as consoantes $b, d, g, k, l, m, n, p, q, r, s, t, z, x, \ll, S, \ddot{y}$, e o sinal '. Por exemplo, toda a palavra acádica que comporte a seqüência P-R-S contém a idéia de "cortar". As vogais e as consoantes duplas servem para atualizar a forma:

PRS: idéia de cortar;

PaRâSum: cortar (infinitivo);

aPRaS: eu cortei;

niPaRRaS: nós cortaremos;

PâRiSum: o cortador.

Neste estágio, não se tratava mais de se escrever um conceito com um sinal, mas de se indicar de maneira precisa, os diversos estados da raiz da palavra. Os acádicos, então, sistematizaram o emprego da escrita fonética, redigindo por sílabas, que eles haviam herda- 
do do velho sistema sumério. Com isso, eles esvaziaram os ideogramas de seu sentido e os reduziram a simples grafias fonéticas.

A primeira consequiência foi um alívio considerável do sistema: não havia mais problema para se representar o som $d u$ : foi escolhido apenas um sinal cuneiforme, e todos os outros dez tornaram-se inúteis. Houve um aumento da capacidade semântica da sílaba. Um sinal foi escolhido dentre todos os seus homófonos e os outros tornaram-se supérfluos, sendo que cada época e região realizou sua própria escolha em meio a um vasto consenso. Tal escolha caracteriza as particularidades regionais ou históricas da escrita dos acádicos.

Utilizar-se-á, como exemplo, a sílaba ša (fig. 11). Constata-se que ša é característica de épocas antigas e médias; $\breve{s a ́, ~ a o ~ c o n t r a ́ r i o, ~ e ́ ~ u t i l i z a d a ~ e m ~ e ́ p o c a s ~ r e c e n t e s, ~ e ~ o ~ s ̌ a ̀ ~ e s t a ́ ~}$ presente somente em textos antigos da região do Elam. Essa diferenciação é de grande ajuda para a identificação das fontes (tabletes, selos, etc.) provenientes de escavações clandestinas ou sem origem precisa, pois, assim, podem-se datá-las e determinar a sua origem geográfica. Existem, aproximadamente, 600 sinais cuneiformes repertoriados.

\section{História dos deciframentos}

A história do deciframento da escrita cuneiforme começou em 1530, com o ensino das disciplinas de Hebreu e Árabe no Collège Royal François Ier, atual Collège de France, em Paris. Essas línguas foram de fundamental importância para a compreensão da escrita cuneiforme. Mas foi, sem dúvida, no começo do século XVIII, com expedições de viajantes às ruínas da cidade de Persépolis, a capital do Império Aquemênida da Pérsia (559-331 a.C.), nos Montes Zagros, que os estudos sobre a Antigüidade Oriental tiveram um grande impulso.

Em 1780, foram descobertas e copiadas por K. Niebuhr parte das inscrições monumentais feitas sobre as paredes dos palácios. A identidade do sítio arqueológico não era conhecida na época, mas, graças a estudos da obra de Heródoto, realizados por historiadores da Grécia Antiga, pode-se inferir sobre Persépolis e reconstituir a seqüência cronológica dos reis persas Ciro, Dario e Xerxes.

Sabe-se que, durante a dinastia aquemênida, a religião do Zoroastro teve grande proeminência e, com ela, o seu deus supremo Ahuramazda. Essa literatura sagrada do Zoroastro, também chamada de Zend-Avesta, já era conhecida dos especialistas europeus graças aos estudos publicados por A. Duperron em 1771. A língua avestan era muito próxima do persa antigo e forneceu numerosas pistas para o seu deciframento.

Assim, o primeiro estudioso a conseguir decifrar alguns caracteres do persa antigo foi Georges Grotefend, um professor alemão que, em 1802, conseguiu ler o nome dos reis Dario (pai) e Xerxes (filho) através de um paralelo com o grego, o hebreu e a língua avestan. Vários estudiosos sucederam-no, entre eles Rasmus Rask, Eugène Burnouf, Christian Lassen, Jules Oppert e Henry Rawlinson, sendo que, em 1847, havia sido realizado o deciframento da totalidade do alfabeto persa antigo.

Contudo, foi, sem dúvida, o inglês Henry Rawlinson quem mais contribuiu para o deciframento da escrita cuneiforme. Desde 1835, ele começou a copiar e a estudar a Inscrição do Rochedo de Behistum, em escrita cuneiforme, em versão trilingüe - persa antigo, elamita e assírio-babilônico. Essa é uma inscrição monumental, realizada pelo rei Dario I, e está localizada ao pé da montanha de Behistum, em um ponto estratégico da rota que ligava Ecbatana à Mesopotâmia. Uma vez que uma das versões, em persa antigo, estava decifrada, foi com menos dificuldades que os outros dois textos foram compreendidos. 
A segunda língua da inscrição de Behistum foi decifrada, em grande parte, por E. Norris entre 1838 e 1851, que constatou tratar-se esta de uma escrita silábica, mais tarde chamada de elamita, porque inúmeros documentos nessa língua foram encontrados na parte sudoeste do Irã, o antigo Elam.

Ao mesmo tempo em que o elamita era decifrado, outros estudiosos, como J. Oppert, W. Talbot, E. Hincks e H. Rawlinson dedicaram-se ao deciframento da terceira escrita, a mais difícil dentre elas, com mais de quatrocentos caracteres diferentes. Através da identificação dos nomes próprios, foi possível reconhecer-se um sistema gráfico, bastante complexo, que utilizava o silabismo juntamente com caracteres ideográficos. A língua, inicialmente chamada de assírio-babilônica, hoje conhecida como acádico, era aparentada das línguas semíticas, como o hebreu, o árabe e o aramaico, e, em 1851, teve o seu deciframento concluído.

Já a língua suméria veio a ser conhecida mais tarde, em 1877, com as descobertas arqueológicas no sítio de Tello, antiga Girsu, feitas por Etienne de Sarzec, vice-cônsul francês em Bassora. Foram exumadas várias estátuas, monumentos e tabletes portando uma grafia em uma língua bastante próxima à dos monumentos assírios já conhecidos, mas com importantes diferenças, que garantiram tratar-se de uma língua até então desconhecida, o sumério. Foi somente em 1905 que se obteve a confirmação dessa descoberta e o estabelecimento da verdadeira importância da civilização suméria, com a publicação das Inscrições de Sumer e Akkad por François Thureau-Dangin (Bottéro, 1987, p. 75-84).

\section{O escriba: um especialista}

Mas, afinal, quem foi o responsável por esta fabulosa inovação na comunicação humana ${ }^{4}$ ? O fato de se saber ler e escrever, no Oriente Antigo, era considerado não somente um privilégio, mas, sobretudo, uma superioridade social. Somente as famílias abastadas podiam assegurar a instrução de um futuro escriba, pois o custo dessa educação era muito elevado e os estudos bastante longos. Os escribas, geralmente, provinham de grandes famílias, que abrigavam funcionários, pessoas responsáveis por grandes extensões de terra, governadores, sacerdotes, ricos mercadores, etc. Outra característica dessa profissão era seu caráter hereditário. Há inúmeros documentos atestando que o ofício de escriba passava de pai para filho.

Conhecemos os nomes de alguns milhares de escribas que se sucederam desde a metade do segundo milênio a.C., pois era padronizado o uso da aposição, no colofão ${ }^{5}$, do nome do redator do texto como garantia de autenticidade do documento.

Conhece-se muito pouco sobre as origens da profissão de escriba ${ }^{6}$, mas, através de textos sumérios tardios, sabemos da importância social desse personagem. Um fato marcante é que, durante o segundo e o primeiro milênios a.C., nenhum escriba registrava a sua posição pessoal, suas idéias ou impressões a respeito do documento que elaborava.

É certo que, com o advento do alfabeto, o prestígio do escriba diminuiu: a maior facilidade permitiu o acesso às práticas de leitura e de escrita à uma camada mais ampla da população.

O escriba precisava, antes de mais nada, dominar as centenas de sinais do sistema cuneiforme, em todos os seus sentidos, conhecê-los e reproduzi-los. Depois disso, que era a base de sua atividade, devia estar apto a redigir cartas e conhecer os formulários dos contratos. Mas ele precisava, também, conhecer as técnicas contábeis que permitiam gerirem-se os grandes patrimônios, garantir a distribuição dos salários sob forma de quantidades de 
cereais, de óleo, de vestimentas, que remuneravam os serviços prestados. Ele devia saber glorificar os altos feitos do rei, compor as inscrições reais, redigir os tratados e as alianças entre os Estados, levando em consideração os hábitos de cada reino. A diversidade de tarefas mostra a importância desse homem na sociedade, sendo que, quanto mais conhecimentos ele possuísse, em cada um desses domínios, mais ele seria procurado e mais teria riqueza e prestígio (Michalowski, 1991, p. 52).

Devemos ressaltar que, a partir da época do rei Hammu-rabi de Babilônia (século XVIII a.C.), as mulheres passaram a ter acesso a essa profissão, como atestam os documentos provenientes de Mari e Sippar (Charpin, 1986, p. 203). Um exemplo disso é uma carta escrita pela princesa Nin-šata-pada, filha do rei Sîn-kãšid de Uruk e sacerdotisa na cidade de Durum, onde a nobre identificava-se como escriba (linha 16 no texto). Assinalamos a raridade de textos provenientes de mulheres-escribas (Hallo, 1968, p. 78). Depois de longas saudações, Nin-šata-płdda implora ao rei Rïm-Sîn que a tenha em consideração e queixa-se do próprio estado físico ${ }^{7}$, do fato de sua família ter sido dispersa e de ela mesma viver no exílio $^{8}$, na condição de escrava, fora da cidade de Durum. Reproduzimos, abaixo, um trecho do documento (Hallo, In: Charpin e Joannès, 1991, p. 380):

mínin-šà-ta-pà-da mídub-sar

nin-dingir dmes-lam-ta-è-a

dumu-mí dEN.ZU-ka-ši-id lugal unu ${ }^{k i}$-ga

géme-zu na-ab-bé-a

("Isso é o que Nin-šata-pada, a mulher escriba, sacerdotisa da divina Meslamtaea, fillha de Sîn-kãšid, rei de Uruk, sua escrava, disse").

\section{As escolas de escribas}

O escriba realizava seu processo de aprendizagem em escolas especializadas, mas é possível que, originalmente, o ensino tenha sido ministrado pelos centros administrativos dos palácios ou dos templos; porém, as informações atuais de que dispomos dão ênfase à existência de escolas privadas, por conseguinte, pagas.

Na segunda metade do terceiro milênio a.C., houve um florescimento do sistema escolar sumério. A escola suméria era chamada de eduba (é.dub.ba.), "casa dos tabletes", em acádico, bît ÿuppi. Foi criada com a finalidade de formar os escribas para trabalharem nas tarefas econômicas e administrativas do país, sobretudo do templo e do palácio. Porém, com o tempo, ela se tornou um centro de difusão da cultura e do saber. Entretanto, até hoje, não podemos descrever, com precisão, como seriam essas escolas, pois não há registros de instalações particulares características. Nessas condições, subsistem poucos elementos característicos: a argila ou os estiletes indicam um local de trabalho e não, necessariamente, de aprendizagem. Um único grupo de objetos, então, é significativo: o dos tabletes escolares (fig. 12). Estes possuem uma forma circular particular, completamente diversa dos formatos habituais utilizados para os atos da administração, afastando, assim, a possibilidade de engano ou dúvida sobre a natureza do documento.

A aprendizagem dava-se de uma maneira bastante simples: através da cópia de um modelo feito pelo professor, onde, um sinal cuneiforme, um grupo de sinais ou uma frase 
escritos sobre uma das faces de um tablete ou em uma linha eram, em seguida, copiados sobre a outra face ou na linha de baixo do modelo.

O estudante aprendia, inicialmente, a forma dos sinais e seu significado. Os exercícios complicavam-se à medida em que avançava o estudo: de sinais simples passava-se a combinações mais complexas, isto é, das sílabas aos ideogramas, depois, às listas de sinônimos ou categorias de objetos, sem se esquecer a gramática; dever-se-ia memorizar a pronúncia, isto é, os valores fonéticos desses sinais; e, em uma etapa posterior, passava-se às obras literárias, que eram copiadas e memorizadas da mesma maneira.

A maioria dos textos escolares era da prática administrativa. Os alunos começavam com exercícios básicos, que facilitavam a aprendizagem dos sinais cuneiformes; depois, procediam à leitura de hinos divinos e reais, cartas literárias, mitos, épicos e outras composições literárias - todas em sumério. Há pequenas evidências de modelos de contratos, de exercícios matemáticos e de cartas em acádico.

As escavações arqueológicas trouxeram, à luz, dois tipos de documentos bastante instrutivos:

- tabletes que continham apenas o início dos textos literários, jamais o final: tratava-se de textos copiados pelos estudantes em nível avançado, como um exercício; quando o professor estimava que os alunos haviam adquirido a técnica necessária para tal tipo de documento, ele decretava o fim do trabalho;

- silabários, também chamados vocabulários, que eram listas de sinais cuneiformes dispostos em estreitas colunas verticais, às vezes, acompanhadas de palavras (de grupos de sinais), destinadas à aprendizagem de mnemotécnicas nas séries de sinais. Esses textos tornaram-se, ainda na Antiguiidade, manuais de referência e, depois, uma fonte importante para os assiriólogos, sobretudo quando se trata de listas bilingües, com o equivalente acádico de palavras sumérias, por exemplo.

Tal como hoje, os antigos professores dependiam de seus salários para viver. A escola suméria, que, provavelmente, começou como uma dependência do templo, tornou-se uma instituição secular e privada. A educação não era nem universal, nem obrigatória. $\mathrm{O}$ ensino se iniciava na infância e seguia até o início da vida adulta.

Sabemos que o professor era chamado de ummia, ou o pai da escola, e os estudantes eram os filhos da escola. Havia vários funcionários, como, por exemplo, o encarregado do desenho, do sumério, da aritmética, da disciplina, etc. Ainda segundo os textos, sabemos que a disciplina era bastante rígida e que os castigos corporais eram habituais na tentativa de correção de erros e insuficiências dos alunos.

O tablete que contém o texto, hoje conhecido como Os Tempos da Escola, trata da situação de um aluno, de sua relação com a escola e com o professor. O texto foi redigido por um professor da escola de escribas, por volta do ano 2.000 a.C., e não se conhece o seu lugar de origem, pois existem várias cópias com fragmentos (Kramer, 1977, p. 268):

- Estudante, onde tu tens ido desde tua primeira infância?

E o estudante responde:

- Tenho ido à escola.

- O que tens feito na escola?

- Decorei o meu tablete, almocei, preparei o meu novo tablete, escrevi-o, terminei-o; depois, apresentaram-me os tabletes de recitação; e, à tarde, trouxeram-me os meus tabletes de exercício. No fim da aula, eu fui 
para casa, entrei em casa e encontrei o meu pai. Expliquei os meus tabletes de exercício ao meu pai, recitei-lhe o meu tablete, e ele ficou deliciado, pois enchi-o de alegria.

O estudante, então, entra na casa dos criados e diz:

- Tenho sede, dá-me água para beber; tenho fome, dá-me pão para comer; lava-me os pés, faz-me a cama, que quero ir deitar-me. Acorda-me de manhã bem cedo, para eu não chegar atrasado, senão, o professor vai me bater com a vara.

Então, no outro dia, pela manhã, o estudante fala que:

- Quando levantei-me de manhãzinha, encarei a minha mãe e disse-lhe: Dê-me o meu almoço, quero ir para a escola! A minha mãe deu-me dois pãezinhos e eu fui para a escola. Na escola, o vigilante encarregado de verificar a pontualidade disse: Por que chegaste atrasado? Temeroso e com o coração batendo, apresentei-me ao professor e fiz-lhe respeitosa reverência.

O meu professor leu o meu tablete e disse:

- Falta aqui qualquer coisa, bateu-me com a vara.

$\mathrm{O}$ vigilante encarregado da limpeza disse:

- Andaste na rua e não cuidaste das tuas roupas, bateu-me com a vara.

O vigilante encarregado da assembléia disse:

- Por que falaste sem autorização?, bateu com a vara.

$\mathrm{O}$ vigilante encarregado do bom comportamento disse:

- Por que te levantaste sem autorização?, bateu com a vara.

$\mathrm{O}$ vigilante encarregado do portão disse:

- Por que saíste sem autorização?, bateu com a vara.

$\mathrm{O}$ vigilante encarregado do sumério disse:

- Por que não falaste sumério?, bateu com a vara.

O meu professor disse:

- A tua ortografia não é satisfatória, bateu com a vara.

E assim eu comecei a odiar a arte de escriba, comecei a negligenciar a arte de escriba.

O meu professor não teve mais alegrias comigo, deixou de me ensinar a arte de escriba.

Desesperado, o estudante voltou-se para o pai e disse-lhe:

- Dá-lhe algum salário suplementar e que ele fique bondoso (...), que ele me corrija também.

Àquilo que o aluno disse, o pai prestou atenção. Convidou o professor e, quando este entrou em casa, fizeram-no sentar na cadeira grande ${ }^{9}$.

O pai ordenou aos criados:

- Derramem-lhe óleo puro, tragam-no para a mesa. Façam com que o óleo corra como água sobre o seu ventre e costas; quero que o vistam com boas roupas, que lhe dêem algum salário extra, lhe ponham um anel no dedo.

Os criados fazem o que lhes foi ordenado, e então o professor diz ao estudante: 
- Jovem, porque não desprezaste as minhas palavras, completarás a arte de escriba desde o princípio até o fim. Porque deste-me tudo sem poupar, pagaste-me um salário maior do que mereço e honraste-me, que Nidaba, a rainha dos anjos da guarda, seja teu anjo da guarda; que teu estilete afiado escreva bem; que teus exercícios não tenham erros. Dos teus irmãos, possas ser o guia; dos teus amigos, possas ser o chefe; que sejas o maior dos formados. (...) Realizaste bem as tarefas escolares, és um homem de saber. Exaltaste Nidaba, a rainha dos estudos!

\section{Conclusão}

A escrita cuneiforme teve uma grande difusão no mundo antigo oriental, tendo sido utilizada na Baixa Mesopotâmia, correspondendo ao atual Iraque, à região da Assíria e da Babilônia e às regiões periféricas, localizadas, atualmente, na Síria, Planalto Anatólico, Armênia, Irã, Chipre, Palestina e mesmo no Egito.

Esse processo de difusão possibilitou, também, a propagação das línguas faladas na Baixa Mesopotâmia, bem como a produção literária dessa região. A língua acádica e a escrita cuneiforme foram, durante longo tempo, na Antigüidade, a linguagem oficial e diplomática entre os diversos povos e impérios. Através delas, estabeleceram-se alianças matrimoniais, tratados de paz, declarações de guerra, etc. As escolas de escribas mesopotâmicas conheceram uma expansão em todo o mundo antigo oriental e proporcionaram o desenvolvimento da escrita das línguas faladas nessas áreas ditas periféricas. Podemos dizer que um dos grandes êxitos das escolas de escribas foi o de terem mantido vivo o ensino do sumério durante cerca de 2000 anos depois de seu desaparecimento como língua falada (de 2000 a.C. a 200 d.C.).

Assim, ao longo dos séculos, uma mesma escrita - a cuneiforme - serviu para representar línguas de estruturas e articulações tão diferentes como o sumério, o elamita, o hurrita, o hatti, o assírio, o babilônico e, esporadicamente, o aramaico, o amorrita, o cananeu e o hitita. Porém, essa escrita, provavelmente, nunca foi “popular", no sentido etimológico do termo: ela sempre permaneceu no domínio de um grupo restrito de especialistas - os escribas - devido às suas dificuldades intrínsecas, que exigiam dedicação e muito tempo para sua aprendizagem.

Longe de ser uma curiosidade, os tabletes cuneiformes são a fonte privilegiada para o estudo da Antigüidade Oriental. A documentação não é nem monótona, nem limitada a uma categoria particular. Seus gêneros vão da literatura elaborada - como os mitos, os textos religiosos e sapienciais - até os textos ditos da prática - como contratos, testamentos, processos, faturas, etc. -, passando por todos os gêneros intermediários, magia, ciências, cartas privadas e textos oficiais da diplomacia ou de historiografia. É, então, através dos tabletes cuneiformes que se pode conhecer e reconstruir esse período da história da humanidade e buscar uma aproximação maior com sua riqueza e complexidade.

\section{Notas}

1 - Pode-se conceituar escrita como um sistema que permite transmitirem-se e fixarem-se línguas, idéias, sentimentos e informações no espaço e no tempo, tendo nascido de imperativos econômicos e sociais ligados ao desenvolvimento das sociedades antigas. 
2 - O tablete de argila possui forma retangular ou quadrada, podendo variar de $3 \mathrm{~cm}$ a mais de $50 \mathrm{~cm}$ de altura.

3 - Os selos-cilindros possuem de 1 a $3 \mathrm{~cm}$ de altura e $2 \mathrm{~cm}$ de diâmetro

4 - Estima-se que os escribas antigos tenham produzido cerca de 1.000 tabletes por dia durante três milênios, o que daria um total de um milhão de documentos

5 - Inscrição no final de documentos contendo o nome do escriba, responsável pela sua execução

6 - O logograma sumério para escriba é DUB.SAR; em acádico, é tupšarru e, em hebreu, tiphsar. Em textos mais recentes, encontra-se o logograma $(L U ́) . A . B A$, traduzido por "o homem do alfabeto".

7 - Nota-se um paralelo entre as linhas 37, 38 e 39 desse texto e as linhas 4' e 10' do reverso da carta. A.1258+S.160SN, editada por Charpin (1992, p. 12 e 21, nota 16).

8 - Entre as seis cópias dessa carta, existe uma variante, que fala de quatro anos de exílio ao invés de cinco.

9 - O lugar de honra, na peça principal da casa, segundo os costumes mesopotâmicos.

\section{Referências bibliográficas}

AMIET, P. L'antiquité orientale. Paris: Presses Universitaires de France, 1995.

BORGER, R. Akkadische Zeichenliste. Vluyn: Verlag Butzon \& Bercker Kevelaer, 1971.

Assyrisch-babylonische Zeichenliste. Vluyn: Verlag Butzon \& Bercker Kevelaer, Bd 33, 1978.

Assyrisch-babylonische Zeichenliste. Vluyn: Verlag Butzon \& Bercker Kevelaer, Bd 33A, 1981.

BOTTÉRO, J. Mésopotamie - L'écriture, la raison et les dieux. Paris: Éditions Gallimard, 1987.

CHARPIN, D. Le clergé d'Ur au siècle d'Hammu-Rabi. Genève-Paris: Droz, 1986.

. Un quartier de Nippur et le problème des écoles à l'époque paléo-babylonienne.

Revue d'Assyriologie et d'Archéologie Orientale, v. 83, 1989. p. 97-112.

Un quartier de Nippur et le problème des écoles à l'époque paléo-babylonienne (suite). Revue d'Assyriologie et d'Archéologie Orientale, v. 84, 1990. p.1-16.

Les malheurs d'un scribe ou de l'inutilité du sumérien loin de Nippur. In: ELLIS, M. Nippur at the centennial-35 R.I.A. Philadelphia, 1992. p.7-27.

DURAND, J.-M. Diffusion et pratiques des écritures cunéiformes au Proche Orient ancien.

In: CHRISTIN, A. M. L'Espace et la lettre. Cahiers Jussieu. Paris: UGE, 1977, p. 13-59.

GARELLI, P. L'assyriologie. Paris: Presses Universitaires de France, 1990.

HALLO, W. W. Individual prayer in Sumerian: the continuity of a tradition. JAOS 88, 1968.

p. $71-89$.

The royal correspondance of Larsa: III. The princess and the plea. In: CHARPIN, D. et JOANNÈS, F. Marchands, diplomates et empereurs. Paris: ERC, 1991. p.377-388. 
. Origins - The ancient Near Eastern background of some modern western institutions. Leiden-New York-Köln: E.J. Brill, 1996.

HROUDA, Barthel. L'Orient Ancien. Paris: France Loisirs, 1992.

KRAMER, S. N. Os sumérios - Sua história, cultura e carácter. Lisboa: Livraria Bertrand, 1977.

LABAT, R.; MALBRAN-LABAT, F. Manuel d'épigraphie akkadienne. Paris: Geuthner, 1988.

MARGUERON, J.-C. Les mésopotamiens. Paris: Armand Colin, 1991. Tome 2.

MICHALOWSKI, P. Charisma and control: on continuity and change in early Mesopotamian bureaucracy systems, In: GIBSON, M. and BIGGS, R. The organization of power: Aspects of bureaucracy in the ancient Near East. Chicago: SAOC 46, 1991. p. 45-57.

POZZER, Katia. “A escrita cuneiforme no antigo Oriente Próximo: Origens e desenvolvimento”. In: BAKOS, M. M. e POZZER, K. M. P. (Org.) Anais da III Jornada de Estudos do Oriente Antigo: Línguas, Escritas e Imaginários. Coleção História 20. Porto Alegre: EDIPUCRS, 1998, p. 39-55.

ROAF, M. Atlas de la Mésopotamie. Paris: Brepols, 1991.

THOMSEN, M.-L. The Sumerian language. Copenhagen: Akademisk Forlag, 1984.

WALKER, C.B.F. Reading the past-cuneiform. London: British Museum Press, 1993.

WILCKE, C. G. L'écriture et la littérature. In: HROUDA, B. L'Orient Ancien - histoire et civilisations. Paris: Éditions Bordas, 1992. p. 271-286.

POZZER, K. M. P. Écritures et scribes - le cunéiforme au Proche-Orient ancien. Classica, São Paulo, 11/12, p. 61-79, 1998/1999.

RÉSUMÉ: L'idée de l'écriture est née à la pré-histoire, mais les documents les plus anciens datent de 3.200 av. J.C. Ce sont des tablettes d'argile avec l'écriture cunéiforme qui ont été trouvés dans la ville d'Uruk, au sud de la Mésopotamie. L'écriture cunéiforme a connu une grande diffusion dans le monde oriental ancien, ayant été utilisée en Basse Mésopotamie, l'actuel Irak, en Assyrie et Babylone et aux régions périphériques, situées, actuellement, en Syrie, Plateau Anatolien, l'Arménie, I'Iran, Chypre, Palestine et même en Egypte. Toutefois, cet écriture, probablement, n'a jamais été "populaire", dans le sens étymologique du terme: elle est toujours restée dans le domaine d'un groupe restreint de spécialistes - les scribes -, cela due à ses propres difficultés, qu'exigeaient beaucoup de temps et de dévouement pour son apprentissage. L'école s'appelait é.dub.ba., en sumérien et bît ÿuppi, en akkadien, traduite par "maison de tablettes". Elle a été créé afin de former des scribes pour travailler dans les tâches économiques et administratives du pays, surtout du temple et du palace. Mais, avec le temps, elle est devenue un centre de diffusion de la culture et du savoir.

MOTS-CLÉS: Écriture cunéiforme; Mésopotamie; scribe; Akkadien; Sumérien; Proche-Orient ancien. 


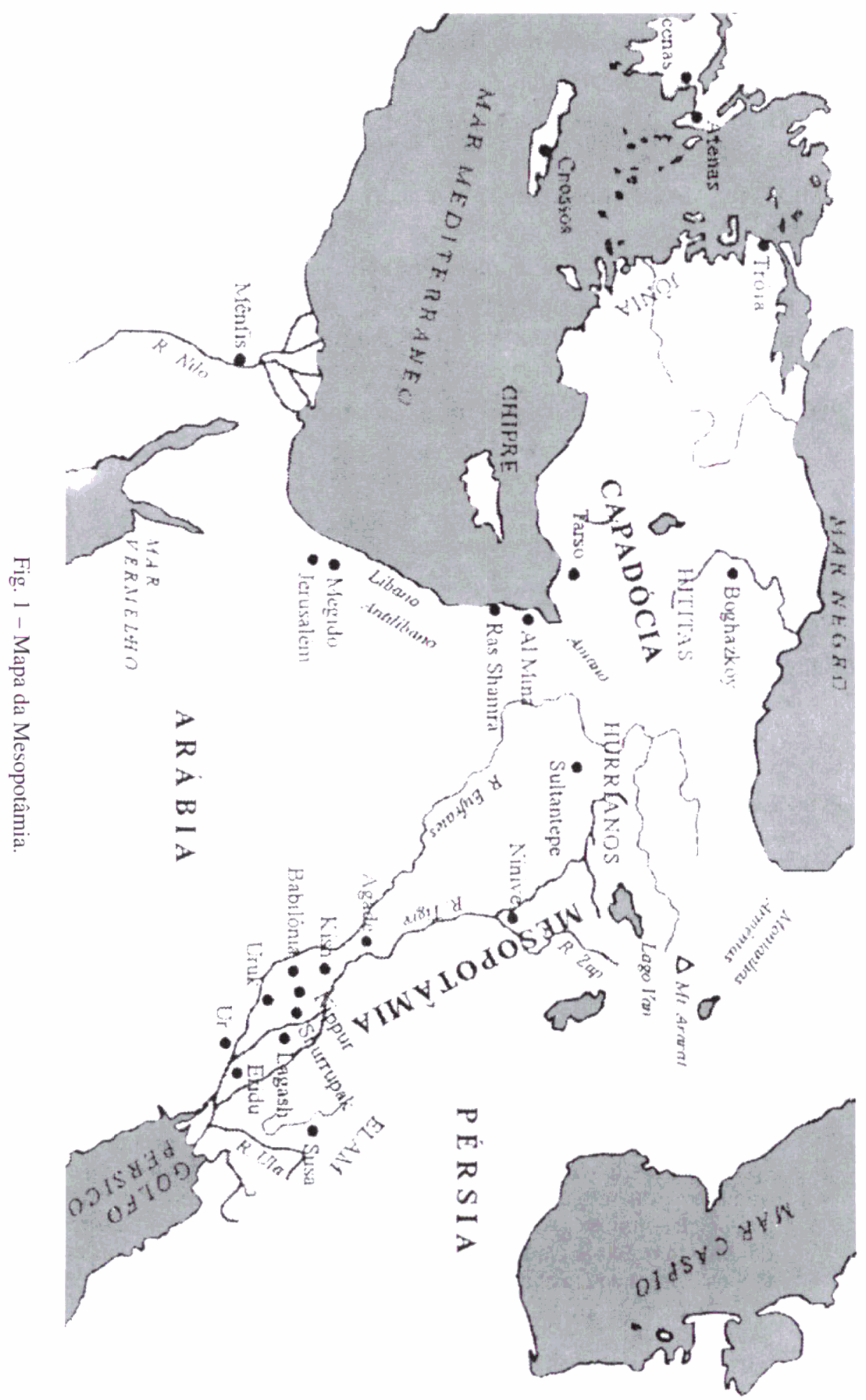



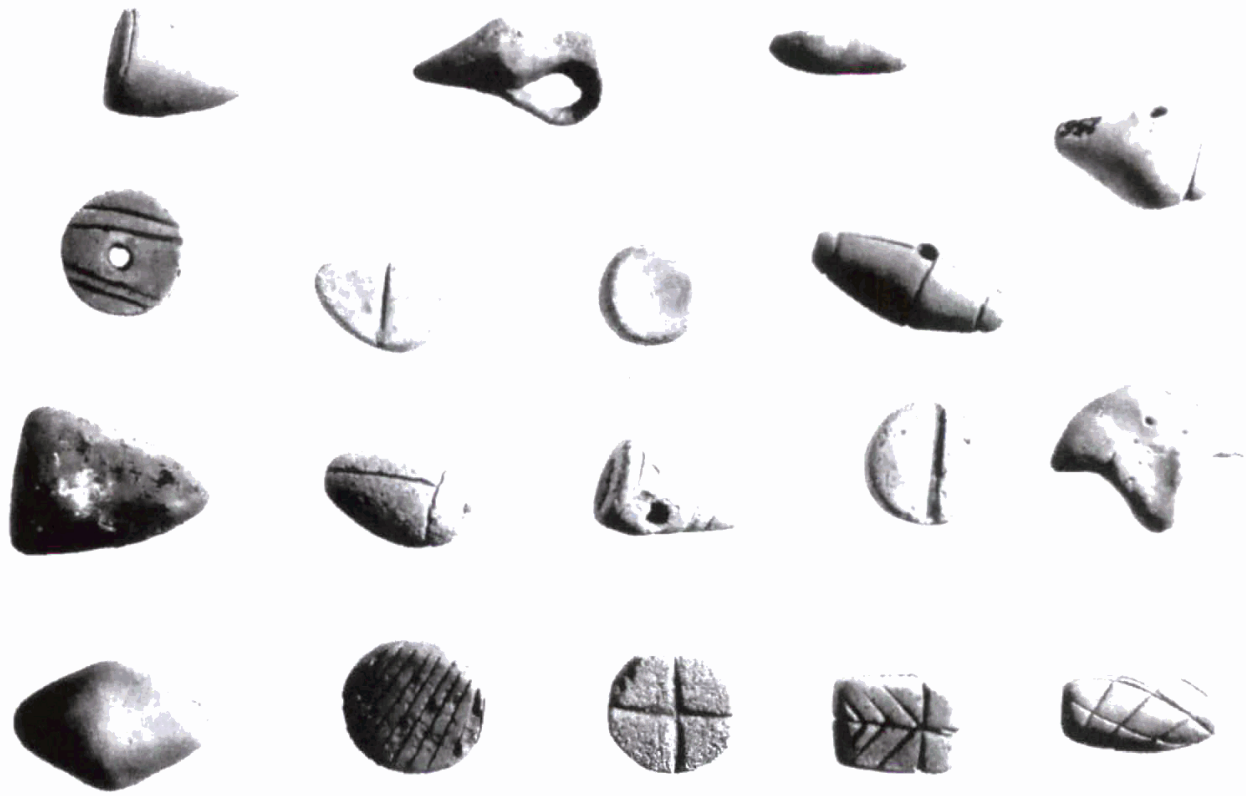

Fig. 2 - Fichas (Hrouda, 1992, p. 272).

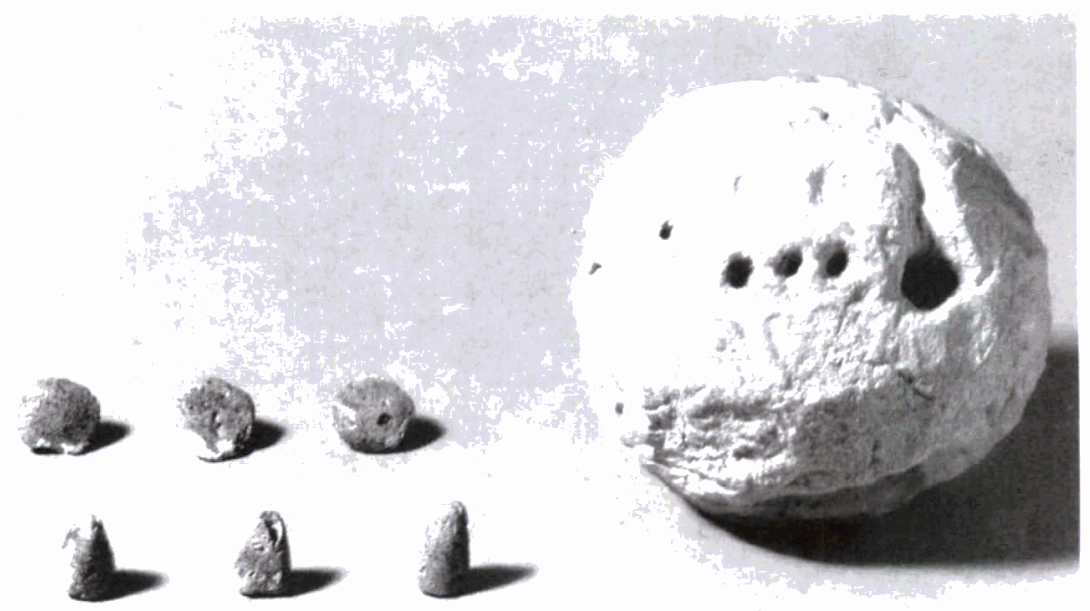

Fig. 3 - Esferas (Hrouda, 1992, p. 273). 


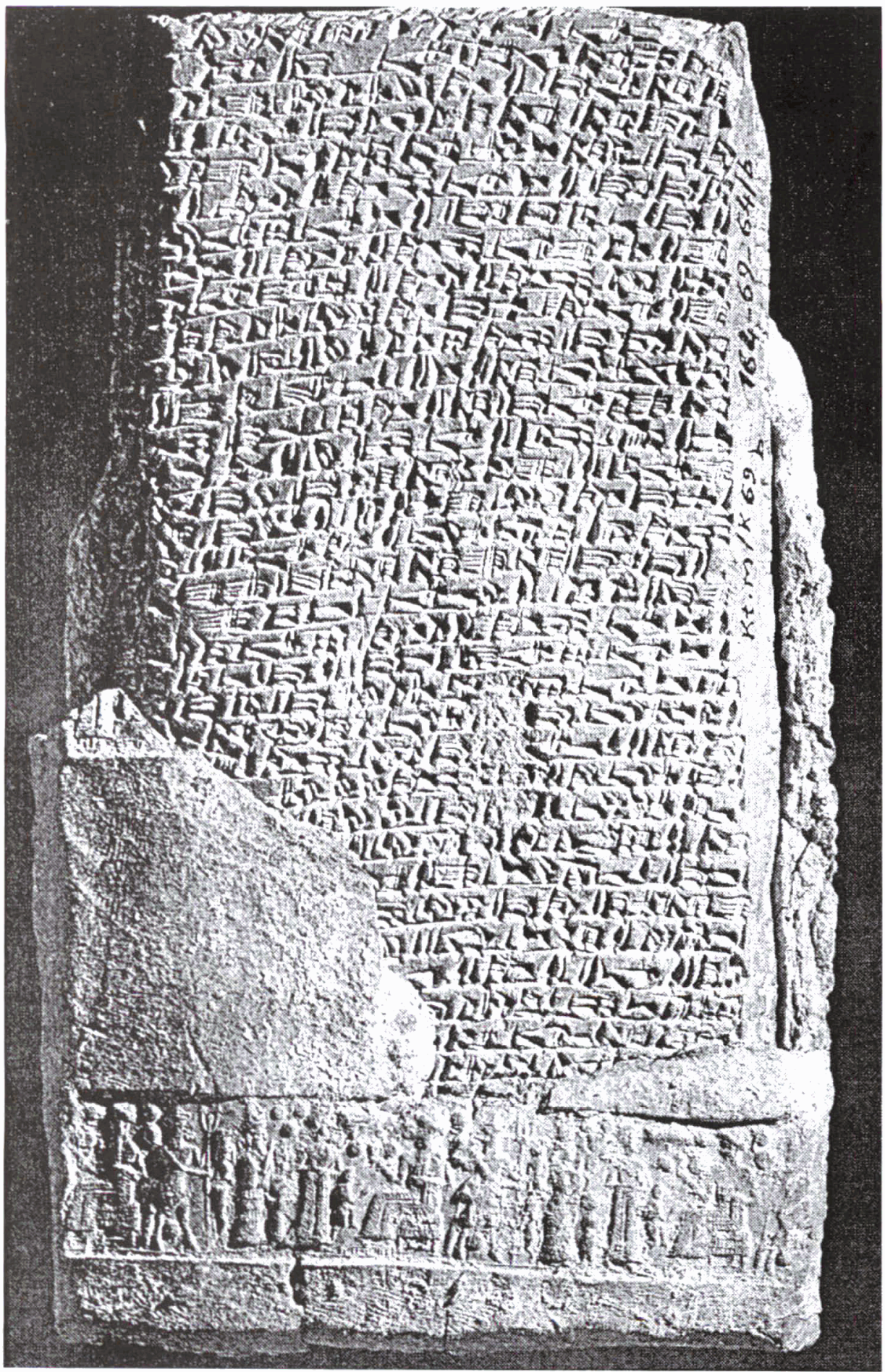

Fig. 4 - Tablete cuneiforme e seu envelope, contendo a impressão de um selo-cilindro (Hrouda, 1992, p. 87). 


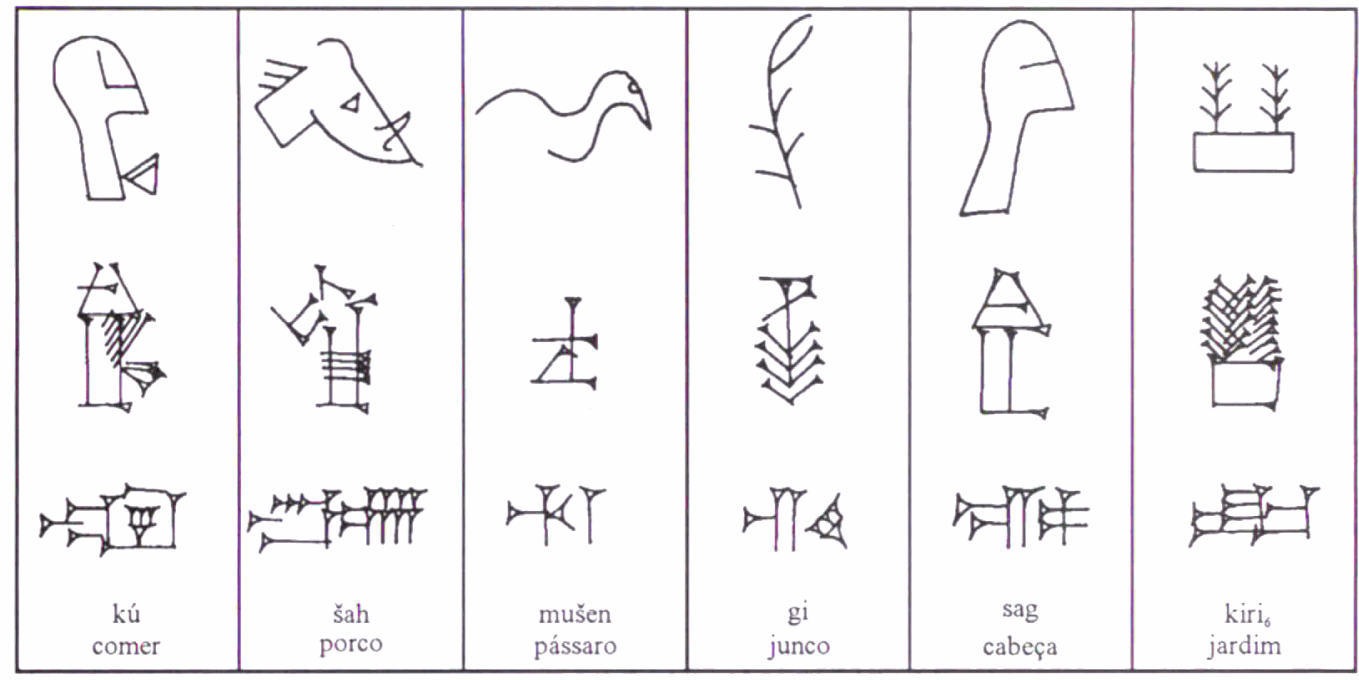

Fig. 5 -Evolução da grafia dos sinais (Walker, 1993, p. 10).

\section{kiri $_{6}=$ jardim}

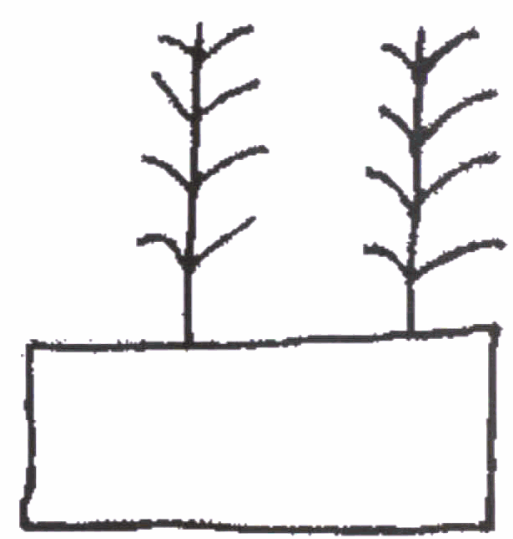

Figura 6 - Representação pictográfica da palavra jardim. 


\section{amigo}

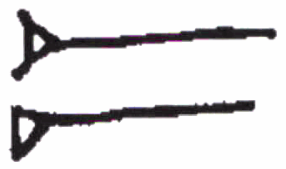

inimigo

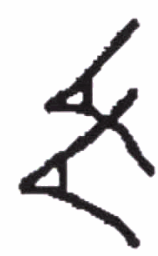

Fig. 7 - Grafia das palavras amigo e inimigo.

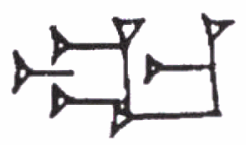

$\mathrm{ka}$

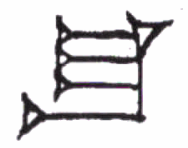

šu

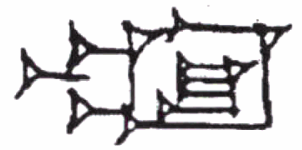

$=$

šud

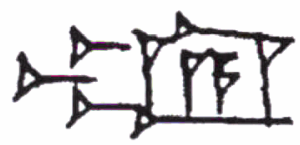

$=\quad$ nag

Figura 8 - Exemplos de justaposição de sinais. 


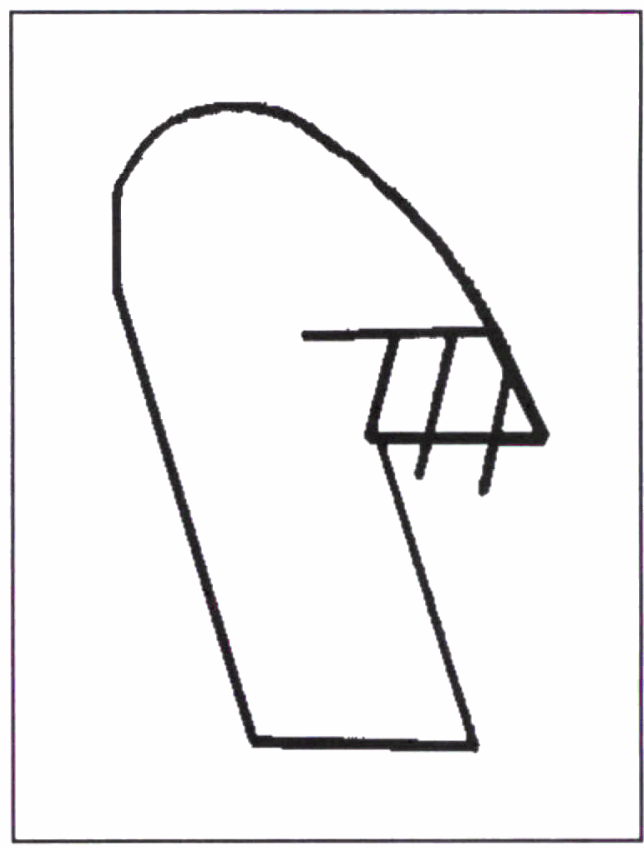

Fig. 9 - Exemplo de polifonia.

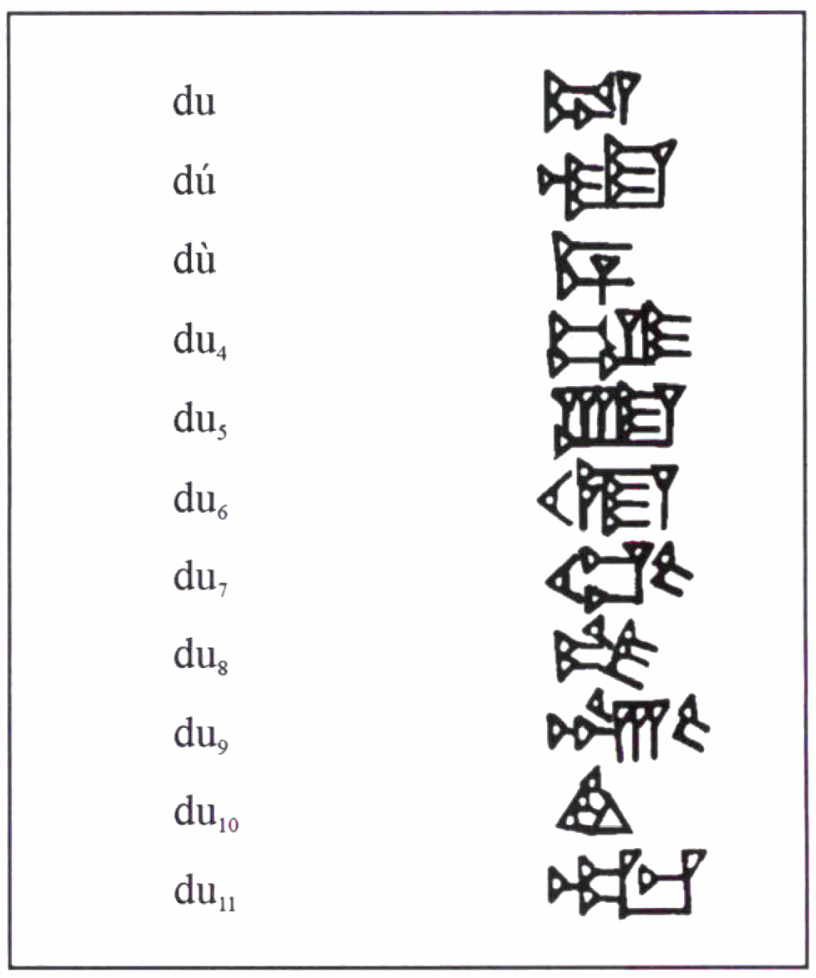

Fig. 10 - Exemplo de sinais homófonos. 

o cuneiforme no antigo Oriente Próximo.

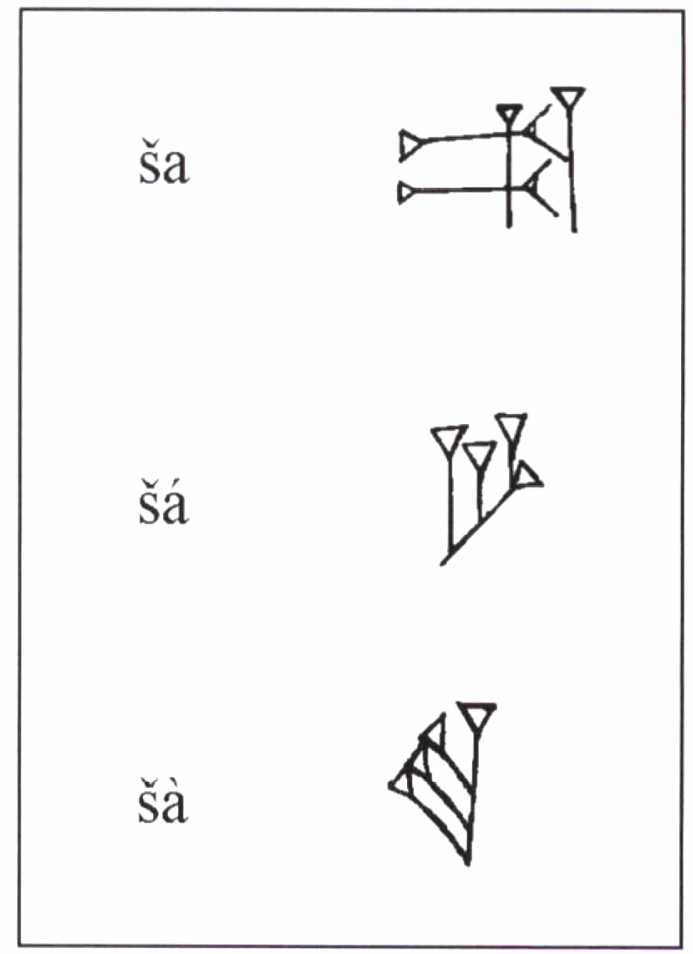

Fig. 11 - Representações da sílaba ša.

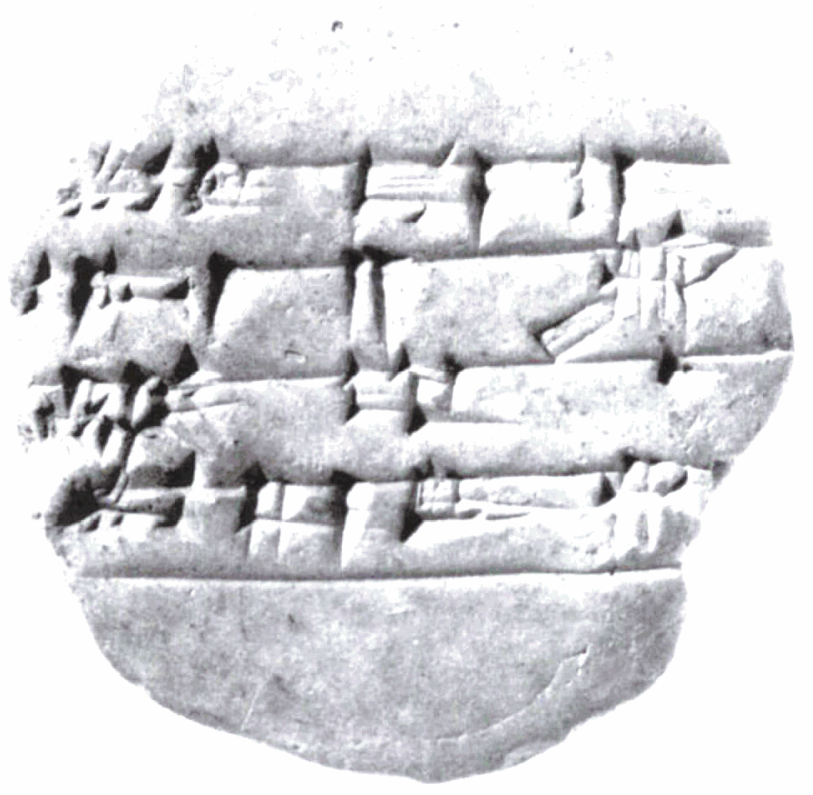

Fig. 12 - Tablete escolar (Walker, 1993, p. 34). 